METALLURGY AND FOUNDRY ENGINEERING - Vol. 37, 2011, No. 1

Jadwiga Kamińska*, Józef Dańko**

\title{
ANALYSIS OF THE GRANULATION PROCESS MECHANISM - STAND AND SCOPE OF EXPERIMENTAL INVESTIGATIONS
}

\section{INTRODUCTION}

Granulation is a process in which primary particles of a dusty material are changing their size forming multiparticle groups called the granulated product. The size of granulated particles is usually within the dimension range from 2 to $40 \mathrm{~mm}$ - in dependence of the aim for which they are being prepared [7].

Granulation falls within the scope of the agglomeration process. In general, it is a conversion of materials of a high degree of fineness into the granulated form. This form has several favourable mechanical features, which make it different from a raw, dusty material [2].

An essence of each granulation method constitutes obtaining a homogeneous product, which consists of granules of the same diameter and the same chemical composition. However, on account of huge amounts of processed substances, the final product granules have, in the end, various dimensions and various chemical compositions.

Granulation of dusty materials is carried out in order to:

- Obtain the determined dimensions, shapes and strength of products, which means: to improve their functional quality,

- Obtain the form of dusty materials acceptable by the market and environment protection,

- Homogenize the composition and properties of materials, which in their initial state differ in compositions, particle shapes and densities,

- Eliminate dusting during the mixing operations,

- Improve flowability and proportioning of dusty materials,

- Eliminate transport problems.

* M.Sc., ** Prof., Ph.D., D.Sc.: Faculty of Foundry Engineering, AGH University of Science and Technology, Kraków, Poland; e-mail: kaminska@agh.edu.pl 


\section{MECHANISMS OF THE GRANULATION PROCESS PRESENTED IN REFERENCES}

An appearance of respectively large forces joining individual grains is the necessary condition of formation a stable agglomerate. Rumpf H. [3] divided the mechanisms of grains binding into 5 categories:

1. Stable bridges, which can be formed at elevated temperatures in grains contact places as the result of the molecule diffusion from one grain to another.

2. Adhesion and cohesion forces occurring in binding substances, which do not allow for a free movement of grains. Substances of a high viscosity (glues) can form bonds similar to the ones which are present in stable bridges.

3. Closed forms of mechanical bonds. They can occur in materials of fibrous and lamellar structures, and also in case of grains which - after undergoing a deformation - are mutually blocking each other.

4. Capillary pressure forces in loosely packed grain systems. These forces can form strong bonds in liquid bridges and capillary spaces, but such bonds will decay when liquid evaporates and there are no other mechanisms which could take these bonds over.

5. Attractive forces interacting between grains, such as van der Waals forces, electrostatic or magnetic forces, which can cause joining of grains in case when these grains are sufficiently close to each other. These forces significantly increase when grain sizes decrease.

Different classification proposed Pietsch W. [4], who divided binding mechanisms into two groups (Fig. 1). Bonds being an effect of attractive forces, based on the law of universal gravitation he rated into one group, while mechanisms which were formed due to the formation of bridged between grains he rated into the second group.

a)

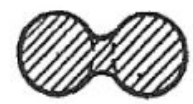

b)

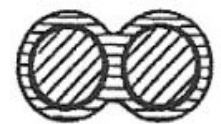

c)

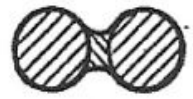

d)

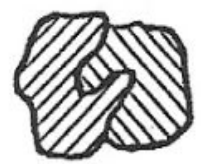

e)

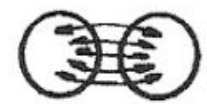

f)

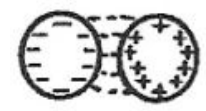

g)

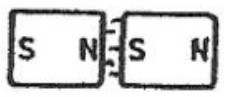

h)

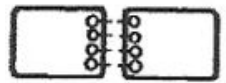

Fig. 1. Binding mechanisms classification acc. to Pietsch [4]: a) chemical reactions, sintering, partial melting; b) adsorption layers; c) liquid bridges; d) closed bonds form; e) molecular and van der Waals forces; f) electrostatic forces; $g$ ) magnetic forces; h) valence forces 
An application of a binding liquid in an agglomeration process significantly facilitates joining of grains. The structure of these agglomerates depends, first of all, on the binding liquid amount. Hewitt D.M. and Conway-Jones J.M. [5] introduced notions of three characteristic states, which they named: pendulous, funicular and capillary (Fig. 2).

a)

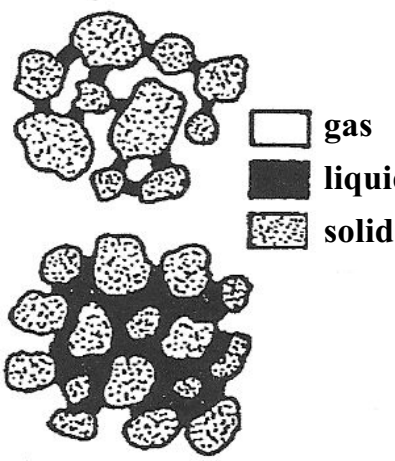

b)

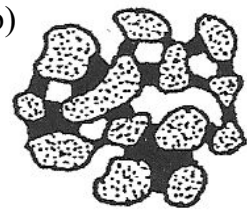

d)

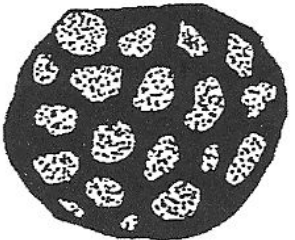

Fig. 2. Different granule structures in dependence of the binding liquid amount [5]: a) pendulous state; b) funicular state; c) capillary state; d) dropping state

A small amount of a binding liquid forms bridges of a lens shape between solid grains - in the pendulous state. Interfacial tension forces at the border: binding liquid-air are negative pressure sources, providing a certain tear resistance for such agglomerate. In the capillary state spaces in between grains are completely filled with a binding liquid. This liquid forms a continuous system inside the agglomerate. Interfacial tension forces appear in this state on the agglomerate surface only and the capillary pressure decides on the granule resistance. The funicular stage is the intermediate one, in which liquid bridges are neighbouring air-filled free intergranular spaces. Thus, the agglomerate resistance - in this state - is determined both by the liquid bridges and capillary pressure.

Apart from three, discussed above, states there is the so-called dropping state (Fig. 2d), occurring when there is an excess of the binding liquid. Thus, such system exist solely due to the surface tension of a liquid drop.

Fisher R.A. [6] provided the theoretical bases of the capillary forces in case of spherical grains. He established that the negative pressure in a liquid phase - being an effect of the meniscus negative curvature - decides on the agglomerate resistance.

The agglomeration process always begins from the nuclei formation, which comes into existence due to joining individual primary grains. Then, at a mutual transferring of granulated materials various mechanisms of growing and reducing of agglomerates occur (Fig. 3). Agglomerates of a relatively weak strength can undergo disintegration as a result of colliding with other aggregates and consequently the granule can be broken into two or more parts (Fig. 3b), or even into primary grains (Fig. 3c). Tearing of individual grains due to abrasion (Fig. 3d), which results in a granule size decreasing, can also occur. During colliding of agglomerate particles a mass transfer from one granule onto the other one can 
also take place (individual grains or their groups). In case when a granule is rolling on a surface formed from individual grains some of those grains are joining the agglomerate. It is vividly often compared to the snowball formation. Such growing mechanism is called building up in layers.

a)

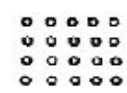

c)

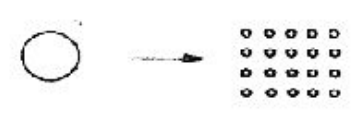

e)

f)

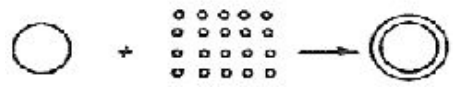

b)

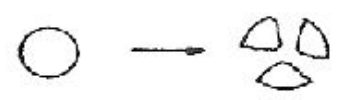

d)
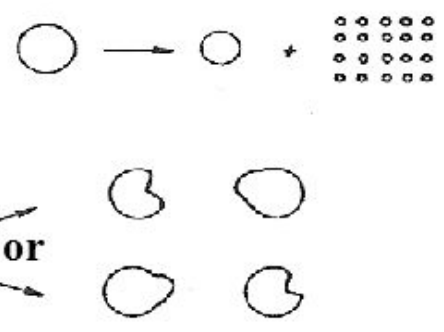

g)

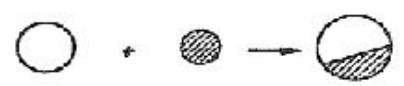

Fig. 3. Basic mechanisms of the formation and changes of granule sizes during the granulation process, acc. to Fisher R.A. [6]: a) nuclei formation; b) breaking up into smaller granules; c) disintegration into primary grains; d) abrasion; e) grain transfer from one granule on the other; f) building up in layers; g) coalescence

A very important mechanism causing a size increase of agglomerates is a phenomenon of coalescence. Granules being in a pendulous or funicular state are characterised by a high plasticity and in effect of a collision are very often joined together. Further influencing of external forces, especially at rolling of the newly formed granules, leads to their formation into a sphere resembling shape. In addition such forces cause that grains or their clusters are coming nearer to each other and driving out air from intergranular spaces. These phenomena are intensified by the influence of the binding liquid surface tension. In consequence, the granule strives to reaching the capillary state, characterised by much higher strength than the pendulous and funicular state. Due to a smaller strength the pendulous and funicular states are less stable and considered the transient ones.

Granulation of powdered materials and the accompanying changes depend, among others, on adhesive and plastic properties of the system: powder + liquid, which in turn is dependent on its moisture content, grain composition and process temperature. Powdered materials granulate the best when their plasticity reaches the highest value and when intermolecular bonds are the most numerous. Also wettability of powders related to effectiveness of influencing solid and liquid phases impacts the granulation process. 
Granulation is carried out [1]:

- from a liquid phase

- from a solid phase

- from a liquid and solid phase.

\section{EXPERIMENTAL STAND FOR TESTING THE GRANULATION PROCESS OF AFTER RECLAMATION DUSTS}

\subsection{Characteristics of the mechanical part of the experimental installation for granulating}

The prototype granulator is characterised by the air-tight sealing of all operations related to proportioning, granulating and emptying, which enables dedusting of these processes at the dust emission level up to $20 \mathrm{mg} / \mathrm{m}^{3}$. The mechanical part of the installation consists of the following functional assemblies:

1. Prototype granulator with a drive allowing for a stepless change of the bowl rotational speed,

2. Weighing and feeding assembly for dusty fractions by means of the encased vibratory feeder together with the dedusting unit,

3. Granulator unloading assembly and granulated product receiver,

4. Unit proportioning a wetting agent,

5. Control system.

\subsection{Description of functional assemblies of the experimental granulator}

The prototype granulator consists of the rotational bowl placed on the axis inclined to the level at the proper angle (there is the possibility of changing this angle). Inside the bowl there are scrapers eliminating dusty accretions on walls and lances with wetting agent feeders, of automated proportioning the wetting agent amount determined in dependence on the charge mass (estimated by weight) as well as the drive allowing for a stepless change of the bowl rotational speed.

Dusty fractions charged into the bowl by means of the feeding screw are weighted together with the bowl system, which casing is placed on the strain gauge weighting system. Proportioning by weight of a granulated dust enables the automatic feeding of the wetting agent in amounts ensuring the granulation process stability as well as the granulated product quality. There is also a possibility of an optional application of one or two units proportioning wetting agents in dependence of dust properties (water for wetting dusts from dedusting of the classic moulding sands processing stations, clays and aluminium processing, or the organic wetting agent for dusts of hydrophobic properties - which are characteristic for: dusty products from coal grinding, carbon electrodes production, systems of processing and reclamation of moulding sands with synthetic resins, powder paint-shops and others). 
The granulator unloading assembly and granulated product receiver allows - after a certain granulation time - to change the inclination angle of the granulator axis in order to accelerate its unloading.

There is a possibility of either automatic or manual control of the granulation process from the control desk. There are also: the safety interlocking system and the succession of technological operations blocking system.

\section{THE RESEARCH SCOPE}

The scientific aim of the research assumes getting to know several physical and chemical properties and structures of dusts with regard to the possibility of selecting the optimal parameters for the dusty material palletising in the prototype granulator as well as the development and verification of the assessment criteria of the final product quality.

The proven methods of physical and chemical examinations of dusts, viscosity and wettability of diphase systems (dust + wetting liquid) measurements, grain-size distribution laser analysis, and the experimental stand of the prototype granulator equipped with the system of measuring the bowl rotational speed, torque moment and the weighing system will be applied in the research.

The practical aim of investigations constitutes the development of guidelines for the management of dusts from dry mechanical reclamation processes of spent foundry sands. It specially concerns hydrophobic dusts e.g. from the reclamation of moulding sands with furfuryl alcohol (the so-called furan sands), which - in their natural dusty form - constitute a harmful waste and their further management is extremely difficult both technically and ecologically.

\section{CONCLUSIONS}

As it was stated above, the essence of agglomeration processes, is increasing particle sizes, in such a way that too high fineness degree or too large scatter of grain size distribution of several raw materials, semi-finished and finished products, will not disturb their application.

Granules can be formed in result of such processes as: agglomeration, building up in layers, enclosing, crystallization or thickening, occurring between components being introduced into the granulator. Whereas fixation of their structure can be carried out by e.g. drying or thermostatic treatment.

Granulation of dusts originated from the reclamation of spent moulding sands, performed with using wetting liquids, occurs in two stages. During the first stage the local activation of dust particles by wetting liquid takes place - leading to the formation of agglomerate nuclei of the capillary or dropping structure. During the second stage the successive agglomerate volume and form building up occurs, which depends on the intensity and character of external forces generated by the operation of the device. 
Physical and chemical properties as well as the dusty material activation are singular features of this material and require the individual approach to the first stage realisation, whereas the mechanism of formation of the agglomerate size and form in the second stage is in the given device the same, regardless of the dusty material and wetting liquid kind.

\section{Acknowledgements}

The study was performed as the Project co-financed by the European Fund of Regional Development within the Operational Program of Innovative Economy, No. WND-POIG.01.03.01-12-007/09.

\section{REFERENCES}

[1] Heim A., Obraniak A., Gluba T.: Wpływ parametrów procesowo-aparaturowych na właściwości złoża podczas granulacji bębnowej, Zeszyty Naukowe Politechniki Łódzkiej, Inżynieria Chemiczna i Procesowa, 29 (2006) 972, 71-79

[2] Rumpf H.: The strength of granules and agglomerates, Agglomeration, Interscience, New York, 1962, pp. $379-414$

[3] Pietsch $W$.: Pressure agglomeration-state of art, Proc. $2^{\text {nd }}$ Int. Symp. on Agglomeration 77, AIME, New York, 1977, pp. 649-677

[4] Newitt D.M., Conwey-Jones J.M.: A Contribution to the Theory and Practice of Granulation, Transaction, Institution of Chemical Eng., 36 (1958), 422-442

[5] Fisher R.A.: On the Capillary Forces in an Ideal Soil, Journal of Agricultural Science, 16 (1962), 492-505

[6] Wesołowski P., Gawałek J.: Wpływ warunków granulacji rozpuszczalnej kawy zbożowej na wydajność procesu i jakość produktu, Przemysł Chemiczny, 87 (2008) 3, 311-314

[7] Dańko J., Kamińska J.: Podstawowe zagadnienia granulacji pyłów poregeneracyjnych, Materiały Konferencji „Quo Wadis Foundry III”, Ekologicke Aspekty Zlievarenstva a Hutnictwa I, Tatranska Lomnica, 5-7 oktobra 2010, pp. 43-48

Received

January 2011 